\title{
Hepatic Resection with in situ Hypothermic Perfusion Is Superior to Other Resection Techniques
}

\author{
Emir Hoti ${ }^{a, b}$ Chady Salloum ${ }^{a}$ Daniel Azoulay ${ }^{a, c, d}$ \\ ${ }^{a}$ Centre Hépato-Biliaire, AP-HP Hôpital Paul Brousse, Villejuif, France; ${ }^{b}$ Liver Transplant Unit, Saint Vincent's \\ University Hospital, Dublin, Ireland; ' INSERM Unité 1004, and d Université Paris-Sud, UMR-S1004, Villejuif, France
}

\section{Key Words}

Liver resection - Total vascular exclusion - Hypothermic perfusion

\begin{abstract}
Through the years, liver resection and bleeding control techniques have progressively evolved. However, for liver tumors located unfavorably, the standard techniques are not suitable due to either failure to control the bleeding or to liver ischemia induced by prolonged interruption of perfusion. In this regard, total vascular exclusion (TVE) with in situ hypothermic perfusion is advantageous as it protects the parenchyma, achieves better vascular control and enables difficult vascular reconstructions or reimplantations. The advantages of this procedure described as early as 1960s by Fortner were also confirmed by our team in a subsequent report. We showed that TVE with in situ hypothermic perfusion is superior to TVE alone if used for more than $60 \mathrm{~min}$ in complex resections with or without vascular reconstruction. Other techniques (ex situ liver resection developed by Pichlmayr and ante situm liver resection by Hannoun) have been described; however, they have not been widely accepted due to a high rate of complications. In this article, we report our operative technique as well as discuss some important operative points.

Copyright $\odot 2011$ S. Karger AG, Basel
\end{abstract}

\section{Introduction}

Technical advances, enhanced understanding of hepatic architecture and physiology, and improved anesthesia and perioperative care have expanded the parameters of hepatic surgery while lowering perioperative morbidity and mortality. At present, hepatic resection has evolved from a high-risk and arduous procedure with a mortality rate of up to $20 \%$ to a standardized procedure with an operative risk of less than $5 \%[1,2]$. These achievements have enabled surgeons to perform hepatic resections previously thought impossible (patients with tumoral involvement of the inferior vena cava (IVC) or those with large centrally located lesions or in close proximity to the confluence of the IVC and hepatic veins) and simultaneously improve the outcome. In the reported series, the 5 -year survival rate after liver resection ranges between 30 and $50 \%$ for both primary and secondary malignancies [3].

This new era of liver surgery has also been marked by the nonvascular-related complications replacing hemorrhage as the principal cause of poor outcome following hepatectomy, especially in patients with underlying liver disease. While portal triad clamping (Pringle's maneuver) [4] or total hepatic vascular exclusion (TVE) [5-7] have proven to be very effective to control hemorrhage

\section{KARGER \\ Fax +4161306 1234 \\ E-Mail karger@karger.ch}

www.karger.com
(C) 2011 S. Karger AG, Basel

0253-4886/11/0282-0094\$38.00/0

Accessible online at:

www.karger.com/dsu
Prof. Daniel Azoulay

Centre Hépato-Biliaire, AP-HP Hôpital Paul Brousse

12 Avenue Paul Vaillant Couturier

FR-94804 Villejuif (France)

Tel. +33 145593 036, E-Mail daniel.azoulay@pbr.aphp.fr 
and air embolism, these techniques have disadvantages ranging from severe hepatic ischemia to hemodynamic disturbances (substantial reduction in cardiac output) and potential renal injury $[8,9]$. Ischemia is a serious problem particularly during complex liver surgery because of the relative time brevity tolerated by liver parenchyma. With longer periods of ischemia necessary for complex liver resections, the impact of any clamping technique is greater due to the ischemic damage per se and the ensuing reperfusion/injury. Damage incurred by postischemic reperfusion to the liver parenchyma and the microvascular system are well established [10, 11], especially so in livers with preexisting cirrhosis and steatosis [12]. Although until lately surgeons considered it safe to occlude the hepatoduodenal ligament in non-cirrhotic livers for up to $90 \mathrm{~min}[13,14]$, the safe duration of the vascular control is uncertain. Therefore, a number of strategies [15-17] to prevent ischemic liver injury were adopted including the technique of in situ hypothermic hepatic perfusion [18]. As in the case of preservation of the liver for transplantation, hypothermic perfusion with cytoprotective solutions in combination with local cooling of the organ's surface has been used to prolong ischemic tolerance.

This review reports on the evolution of the in situ hypothermic liver preservation technique, examines some of the advantages concerning the safety and efficacy and in addition provides some important surgical details of this technique.

\section{Evolution of Liver Resection Techniques Combined with Hypothermic Perfusion}

W.P. Longmire was the first surgeon to report in 1961 the use of hypothermia induced by external body cooling during a hepatectomy [19]. Ten years later (1971), Fortner et al. [18] reported in situ hypothermic hepatic perfusion with chilled Ringer's solution for major liver resection. Subsequently, in the 1980s several authors reported major hepatic resections using profound hypothermia and circulatory arrest in selected patients with large liver tumors $[20,21]$. In the technique described by Fortner et al. [18], the hypothermia was induced by perfusing the liver via the arterial and portal system with cold Ringer's solution $\left(4^{\circ} \mathrm{C}\right)$. Later on, influenced by the experience gained with the reduced-size liver transplantation, Pichlmayr et al. [22] designed the technique of ex situ liver resection. The main steps of this technique include the installation of TVE, venovenous bypass, and the removal of the whole liver. The latter is then perfused ex situ via portal and arterial system with HTK solution (used for liver graft preservation). The liver is maintained in cold HTK solution packed with ice for optimal preservation during bench hepatectomy. The remaining liver is reimplanted using the same technique as the one for reduced-size graft. To improve the access to the posterior aspect of the liver without resorting to the division of the portal triad, Hannoun et al. [23] designed the so-called ante situm technique in which the hepatic veins are divided, allowing mobilization of the liver anteriorly. During the procedure, the liver is placed on a heat exchanger $\left(4^{\circ} \mathrm{C}\right)$. The future remnant liver is perfused with the Belzer's [24] University of Wisconsin solution chilled at $4^{\circ} \mathrm{C}$ (UW solution) via the portal vein or the hepatic artery. The remaining hepatic veins are reimplanted into the vena cava. Finally, Belghiti et al. [25] described a variation of the latter technique in which the vena cava is cut above and below the liver, enabling the resection to be done while the liver is being perfused to induce the hypothermia via the portal vein. The vena cava is reconstructed after liver resection.

Another interesting modification is the hemihepatic hypothermic perfusion with hepatoprotective agents during right-sided hepatic resection for deeply situated tumors in patients with coexisting liver disease. This technique, first described by Yamanaka et al. [26, 27] in 1993, does not require a venovenous bypass because the left-sided hepatic blood flow and vena cava blood flow are preserved. Following occlusion of the right hepatic vein and the right portal pedicle, in situ cold perfusion is initiated using chilled Ringer's lactate solution through a cannula placed in the right main portal branch under ultrasound guidance. The liver is cooled to $22-26^{\circ} \mathrm{C}$ for $40-80$ min without any significant changes in systemic hemodynamics, body temperature, or postoperative liver function. The hemihepatic hypothermic perfusion method is also rather cumbersome, requiring isolation of the right hepatic vein and precise placement of the tip of the perfusion catheter in the first branch of the portal vein via the mesenteric vein. Some branches of the hepatic vein on the dissected surface are left open to drain the perfusate.

\section{Specific Technical Aspects}

\section{Anesthetic Management}

This type of surgery should be performed always with anesthesiologists who have experience with liver transplantation and are able to manage prolonged IVC occlusion and the changes that occur with liver reperfusion. 
During surgery, all patients are monitored by standard noninvasive techniques. In addition, patients planned to undergo TVE with hypothermic perfusion have a SwannGanz catheter and an arterial line placed before surgery. Body warmers are routinely employed to prevent hypothermia intraoperatively.

\section{Surgical Exploration}

We routinely use a bilateral subcostal incision which provides adequate exposure for almost all types of liver resection. It is imperative to carefully explore the abdominal cavity for extrahepatic and peritoneal metastases. Any suspicious nodule should be examined by frozen section. A double examination of the liver by palpation and ultrasonography is performed, to confirm the number and size of the lesions, to define their relationship to intrahepatic vascular structures, exclude undiagnosed liver metastases and lastly to determine the resection line. The next step after the systematic exploration is to obtain the TVE. Depending on the individual patients this step can be combined with the installation of the venovenous bypass (if hemodynamic intolerance is observed).

\section{Vascular Control of the Liver}

In our center, the vascular control is planned preoperatively based on the morphologic evaluation of the liver anatomy and relation/s of the tumor with important structures. The technique of total vascular exclusion of the liver (TVE) we use involves mobilization of the liver, exposure and control of the suprahepatic and infrahepatic vena cava as well as the portal structures (portal vein and hepatic artery). To achieve the exposure of the vena cava, a systematic ligation and division of the right adrenal vein is necessary. Once the above step is completed, the infrahepatic vena cava, portal structures and suprahepatic vena cava are sequentially clamped. With this technique, the use of venovenous bypass is relatively high due to hemodynamic intolerance characterized by a decrease in mean arterial pressure $>30 \%$ and/or a decrease in cardiac index $>50 \%$.

\section{In situ Hypothermic Perfusion of the Liver}

Generally, in situ hypothermic perfusion of the liver is applied in conjunction with TVE for complex resections which may include also vascular reconstruction (vena cava, hepatic vein and/or portal vein resection). The in situ hypothermic perfusion technique we use is similar to the one described by Fortner et al. [18], albeit with some modifications. When using a venovenous bypass, the systemic and splanchnic blood return via the right femoral and inferior mesenteric vein is diverted to left internal jugular vein. The puncture and cannulation of femoral and left axillary vein is done under ultrasound control. Following TVE and installation of the venovenous bypass, the preparation for hypothermic perfusion is done. A small purse string 6/0 polypropylene suture is placed in the anterior wall of the portal vein. A venotomy is done at the same site and the portal vein is cannulated above the portal clamp with a Silastic catheter, which is secured with the ends of the purse-string suture. The main portal vein, proper hepatic artery and common bile duct are occluded individually with appropriate vascular clamps. Vascular clamps are then placed on the infrahepatic and suprahepatic vena cava, completing the total hepatic vascular exclusion. Crushed ice is placed around the liver and the preservation solution (UW) cooled to $4^{\circ} \mathrm{C}$ is then commenced via the inflow Silastic catheter, with the perfusate solution positioned at a height of $0.5 \mathrm{~m}$. A cavotomy is always performed just above the inferior caval clamp to enable the drainage of the perfusate. The catheterization via 30 -Fr catheter of the cavotomy is necessary as it prevents the spill of the cold perfusate in the peritoneal cavity, in turn decreasing the core temperature of the patient. We run the first liter wide open in order to cool the liver rapidly and then the rate is slowed to maintain a constant low temperature of the liver (roughly 1 liter every 15-20 min). Next step involves the division of the hepatic parenchyma under TVE, followed by the vascular reconstruction (when necessary), paying special attention to the correct orientation of the liver to ensure good outflow.

\section{Reperfusion}

After informing the anesthetist to be prepared for release of the vascular clamps, the liver is flushed with serum albumin via the portal vein. The portal cannula for perfusion is removed and the portotomy and the cavotomy are closed. The suprahepatic clamp is the first to be released, followed by the infrahepatic one. The portal vein clamp is then released slowly as dictated by the patient's hemodynamics. Finally, hemostasis of the remaining hepatic parenchyma is performed. The venovenous bypass is removed as the last step, after hemodynamic stabilization. The inferior mesenteric vein is ligated, whereas the hemostasis at the femoral and jugular puncture sites is achieved with cutaneous sutures.

\section{Perioperative Care}

All our patients are admitted for the first 24 postoperative hours to the intensive care unit where they would 
be extubated provided that they are hemodynamically stable, normothermic and without base deficits.

\section{Anticoagulation Protocol}

We anticoagulate patients with vascular reconstruction (caval and/or hepatic vein/s). Anticoagulation with intravenous heparin is commenced in the operating theater at $1 \mathrm{mg} / \mathrm{kg}$ body weight $/ 24 \mathrm{~h}$, and the dose is titrated to maintain the coagulation time between 1.5 and 2 times the normal level. The intravenous heparin is maintained for 8 days and then replaced by daily injection of lowmolecular-weight heparin for 1 month. Long-term anticoagulation is not applied. On the other hand, patients in whom only a vascular plasty is performed receive one daily injection of low-molecular-weight heparin from day 1 to discharge from hospital.

\section{Comment}

\section{Impact of TVE}

The in situ hypothermic perfusion of the liver is a useful adjunct to complex hepatobiliary surgery that requires TVE. Although TVE was introduced in 1966 [5], the acceptance and adoption of this technique has occurred only during the last 2 decades. Minimal blood loss during parenchymal transection is the principal benefit associated with TVE. The liver substance can be divided in a virtually bloodless field, allowing precise identification of vessels and bile ducts, which can either be controlled and preserved or divided and reconstructed. However, as this technique was increasingly being used for very complex resections (hepatectomy up to six segments or after aggressive preoperative chemotherapy), it became obvious that the earlier guidelines of safe clampage time of the liver became questionable due to induced ischemia and subsequent ischemia-reperfusion injury (particularly pronounced if TVE $>60 \mathrm{~min}$ ). Hence, the protection and preservation of the functional reserve of the future liver remnant became primordial. To this end, the introduction of in situ hypothermic perfusion of the liver, combined with packing of the liver remnant in ice, has played a major role [18]. Several authors have advocated the use of combined TVE with in situ hypothermic perfusion of the liver [18, 28-31]; however, the largest series to date of combined TVE with in situ hypothermic perfusion of the liver comes from our center [30]. Hypothermic perfusion of the liver allows prolongation of the duration of TVE and subsequent safe performance of hepatectomies that are otherwise technically possible but contraindicated due to the risk of postoperative liver failure following long warm ischemia time. In our experience, this technique works extremely well for two clinical situations: (1) large tumors arising from or impinging on the retrohepatic vena cava or the confluence of the IVC and hepatic veins necessitating a TVE time of $>60 \mathrm{~min}$ [30], and (2) liver resections in patients with compromised parenchyma (steatosis/fibrosis after aggressive preoperative chemotherapy) [29].

\section{Impact of in situ Hypothermic Perfusion}

Preservation of liver function and diminished impact of ischemia-reperfusion injury have been the most obvious consequences of hypothermic perfusion as demonstrated by our series and also by other reports $[28,30]$. We were the first group to demonstrate that hypothermic perfusion of the liver is followed by a significantly better tolerance to ischemia, a better liver function, and significantly lower complication rate compared to standard TVE $>60$ min [28]. In addition, we showed that the results obtained with hypothermic perfusion of the liver are comparable to or even better than those obtained following liver resection with standard TVE $<60 \mathrm{~min}$. Supporting evidence that the use of in situ hypothermic liver perfusion facilitates radical hepatectomies with or without vascular reconstruction comes also from experimental studies. For example, while using hypothermic liver preservation it has been shown that for every $10^{\circ} \mathrm{C}$ decline of the temperature of liver parenchyma, the activity of most enzyme systems decreases by 1.5 - to 2.0 -fold [32]. In addition, researchers have demonstrated that using hypothermic liver perfusion during liver resections leads to decreased levels of aspartate and alanine aminotransferases, decreased interleukin 6 levels, preserved indocyanine green clearance, preserved sinusoidal endothelial cell function, reduced vascular permeability of the liver and the other splanchnic organs, increased partial pressure of oxygen, higher glutathione content, and preserved bile production when compared with (warm) TVE [3336].

As mentioned earlier in this paper, besides the TVE with in situ hypothermic perfusion, two other approaches are distinguished: (1) ex situ resection with complete removal of the liver from the body and resection as a bench procedure [22], and (2) ante situm resection with dissection of the suprahepatic IVC only [23]. Compared with the in situ and ante situm techniques, the ex situ technique includes the division and the reconstruction of the portal triad following bench hepatectomy. The specific additional morbidity and mortality of this triple re- 
construction (i.e. the portal vein, the hepatic artery, and the bile duct/s) could explain the different results when comparing the ex situ technique to the other two. The reported postoperative mortality has been as high as $28 \%$ with some cases necessitating salvage liver transplantation due to fulminant hepatic failure [37-44]. Taking into account these results and the present shortage of liver grafts, the general opinion is that the ex situ technique should be considered with caution.

\section{Conclusion}

Among the different methods of vascular control, the experience has indicated that for hepatic tumors located centrally, tumors involving major vascular structures or those requiring lobectomy or extended lobectomy, only the use of TVE with hypothermic perfusion enables complex liver surgery and provides a margin of safety. This method in experienced hands results in equivalent resection margins and decreases the incidence of postoperative complications, especially liver failure due to prolonged ischemia.
It is advocated that the use of in situ hypothermic perfusion of the liver should be planned prior to surgery when dealing with patients necessitating TVE $>60 \mathrm{~min}$ [30]. Factors such as preoperative portal vein embolization and/or large tumors are predictive of TVE $>60 \mathrm{~min}$ [30].

Lastly, considering the fact that in situ hypothermic perfusion of the liver is well tolerated indicates that its indications should be broadened. This technique could be used not only for patients with predictive factors for TVE $>60 \mathrm{~min}$, but also for patients whose liver resections could be performed within $1 \mathrm{~h}$ of TVE. It could be particularly useful for patients with chronic liver disease, as already demonstrated by a number of reports $[37,45]$.

\section{Disclosure Statement}

The authors have nothing to disclose.

\section{References}

1 Capussoti L, Polastri R: Operative risk of major hepatic resections. Hepatogastroenterology 1998;45:184-190.

2 Jarnagin WR, Gonen M, Fong Y, et al: Improvement in perioperative outcome after hepatic resection: analysis of 1,803 consecutive cases over the past decade. Ann Surg 2002;236:397-406.

3 Simmonds PC, Primrose JN, Colquitt JL, et al: Surgical resection of hepatic metastases from colorectal cancer: a systematic review of published studies. Br J Cancer 2006;94: 982-999.

4 Pringle JH: Notes on the arrest of hepatic hemorrhage due to trauma. Ann Surg 1908; 48:541.

5 Heany JP, Stanton WK, Halbert DS, Seidel J, Vice T: An improved technique for vascular isolation of the liver: experimental study and case reports. Ann Surg 1966;163:237-241.

6 Bismuth H, Castaing D, Garden O: Major hepatic resection under total vascular exclusion. Ann Surg 1989;210:13-19.

7 Huguet C, Addario-Chieco P, Gavelli A, Arriogo E, Harb J, Clement RR: Technique of hepatic vascular exclusion for extensive liver resection. Am J Surg 1992;163:602-605.
8 Emond JC, Kelley SD, Heffron TG, Nakagawa T, Roberts JP, Lim RC Jr: Surgical and anesthetic management of patients undergoing major hepatectomy using total vascular exclusion. Liver Transplant Surg 1996;2:91-98.

9 Belghiti J, Noun R, Zante E, Ballet T, Sauvanet $\mathrm{A}$ : Portal triad clamping or hepatic vascular exclusion for major liver resection. Ann Surg 1996;224:155-161.

10 Dinant S, van Veen SQ, Roseboom HJ, van Vliet AK, van Gulik TM: Liver protection by hypothermic perfusion at different temperatures during total vascular exclusion. Liver Int 2006;26:486-493.

11 Menger MD, Richter S, Yamauchi J, Vollmar $\mathrm{B}$ : Role of microcirculation in hepatic ischemia/reperfusion injury. Hepatogastroenterology 1999;46:1452-1457.

12 Vetelainen R, van Vliet A, Gouma DJ, van Gulik TM: Steatosis as risk factor in liver surgery. Ann Surg 2007;245:20-30.

13 Huguet C, Gavelli A, Chieco PA, et al: Liver ischemia for hepatic resection: where is the limit? Surgery 1992;111:251-259.

14 Hannoun L, Borie D, Delva E, et al: Liver resection with normothermic ischaemia exceeding 1 h. Br J Surg 1993;80:1161-1165.
15 Malassagne B, Cherqui D, Alon R, et al: Safety of selective vascular clamping for major hepatectomies. J Am Coll Surg 1998;187: 482-486.

16 Aldrighetti L, Pulitano C, Arru M, et al: Impact of preoperative steroids administration on ischemia-reperfusion injury and systemic responses in liver surgery: a prospective randomized study. Liver Transpl 2006;12:941949.

17 Beck-Schimmer B, Breitenstein S, Urech S, et al: A randomised controlled trial on pharmacological preconditioning in liver surgery using a volatile anesthetic. Ann Surg 2008; 248:909-919.

18 Fortner JG, Shiu MH, Kinne DW, et al: Major hepatic resection using vascular isolation and hypothermic perfusion. Ann Surg 1974; 180:644-652.

19 Longmire WP, Marable SA: Clinical experiences with major hepatic resections. Ann Surg 1961; 154:460.

20 Ein SH, Shanding B, Williams WG, Trusler G: Major hepatic tumor resection using profound hypothermia and circulation arrest. J Pediatr Surg 1981;16:339.

21 Goh DW, Gornall P, Roberts KD, Willetts R, Stevens MCG: Hepatic tumour resection with profound hypothermia and circulatory arrest. Br J Surg 1989;76:548. 
22 Pichlmayr R, Grosse H, Hauss J, et al: Technique and preliminary results of extracorporeal liver surgery (bench procedure) and of surgery of the in situ perfused liver. Br J Surg 1990;77:21-26.

23 Hannoun L, Panis Y, Balladur P, et al: Exsitu in-vivo liver surgery. Lancet 1991;337: 1616-1617.

24 Belzer FO, Southard JH: Principles of solidorgan preservation by cold storage. Transplantation 1988;45:673-676.

25 Belghiti J, Dousset B, Sauvanet A, et al: Résultats préliminaires de l'exérèse $<$ ex situ $>$ des tumeurs hépatiques: une place entre les traitements palliatifs et la transplantation. Gastroentérol Clin Biol 1991;15:449-453.

26 Yamanaka N, Okamoto E, Fujiwara S, et al: Hepatic resection under liver surface or perfusion cooling together with hepatoprotective agents of PGE1 and urinastatin (in Japanese). Nippon Geka Gakkai Zassi 1993;94: 259-268.

27 Yamanaka N, Okamoto E, Furukawa K, et al: Hepatic resection under in situ hemihepatic hypothermic perfusion with hepatoprotective agents. Hepatogastroenterology 1995 42:1.

28 Hemming AW, Reed AI, Langham MR, et al: Hepatic vein reconstruction for resection of hepatic tumors. Ann Surg 2002;235:850858.

29 Kaiho T, Tanaka T, Tsuchiya S, et al: Hepatic resection under in situ hypothermic hepatic perfusion. Hepatogastroenterology 2003;50: 761-765.
30 Azoulay D, Eshkenazy R, Andreani P, Castaing $\mathrm{D}$, Adam $\mathrm{R}$, et al: In situ hypothermic perfusion of the liver versus standard total vascular exclusion for complex liver resection. Ann Surg 2005;241:277-285.

31 DuBay D, Gallinger S, Hawryluck L, Swallow C, McCluskey S, McGilvray I: In situ hypothermic preservation during radical liver resection with major vascular reconstruction. Br J Surg 2009;96:1429-1436.

32 Belzer FO, Southard JH: Principles of solidorgan preservation by cold storage. Transplantation 1988;45:673-676.

33 Heijnen BH, Straatsburg IH, Kager LM, van der Kleij AJ, Gouma DJ, van Gulik TM: Effect of in situ hypothermic perfusion on intrahepatic $\mathrm{pO}_{2}$ and reactive oxygen species formation after partial hepatectomy under total hepatic vascular exclusion in pigs. Liver Int 2003;23:19-27.

34 Heijnen BH, Straatsburg IH, Gouma DJ, van Gulik TM: Decrease in core liver temperature with 10 degrees $\mathrm{C}$ by in situ hypothermic perfusion under total hepatic vascular exclusion reduces liver ischemia and reperfusion injury during partial hepatectomy in pigs. Surgery 2003;134:806-817.

35 Dinant S, van Veen SQ, Roseboom HJ, van Vliet AK, van Gulik TM: Liver protection by hypothermic perfusion at different temperatures during total vascular exclusion. Liver Int 2006;26:486-493.

36 Dinant S, Roseboom HJ, Levi M, van Vliet AK, van Gulik TM: Hypothermic in situ perfusion of the porcine liver using Celsior or Ringer lactate solution. Langenbecks Arch Surg 2009;394:143-150.

37 Kumada K, Yamaoka Y, Morimoto T, et al: Partial autotransplantation of the liver in hepatocellular carcinoma complicating cirrhosis. Br J Surg 1992;79:566-567.
38 Yanaga K, Kishikawa K, Shimada M, et al: Extracorporeal hepatic resection for previously unresectable neoplasms. Surgery 1993; 113:637-643.

39 Yagyu T, Shimizu R, Nishida M, et al: Reconstruction of the hepatic vein to the prosthetic inferior vena cava in right extended hemihepatectomy with ex situ procedure. Surgery 1994;115:740-744.

40 Wakabayashi $\mathrm{H}$, Maeba T, Okano K, et al: Treatment of recurrent hepatocellular carcinoma by hepatectomy with right and middle hepatic vein reconstruction using total vascular exclusion with extracorporeal bypass and hypothermic hepatic perfusion: report of a case. Surg Today Jpn J Surg 1998;28:547550 .

41 Lodge JPA, Ammori BJ, Prasad R, et al: Ex vivo and in situ resection of inferior vena cava with hepatectomy for colorectal metastases. Ann Surg 2000;231:471-479.

42 Oldhafer KJ, Lang H, Schlitt HJ, et al: Longterm experience after ex situ liver surgery. Surgery 2000;127:520-527.

43 Hemming AW, Reed AI, Langham MR, et al: Hepatic vein reconstruction for resection of hepatic tumors. Ann Surg 2002;235:850858.

44 Lechaux D, Magavand JM, Raoul JL, et al: Ex vivo right trisegmentectomy with reconstruction of inferior vena cava and 'flop' reimplantation. J Am Coll Surg 2002;194:842845

45 Ohwada S, Ogawa T, Kawashima Y, et al: Concomitant major hepatectomy and inferior vena cava reconstruction. J Am Coll Surg 1999;188:63-71. 